\title{
Sala de Emergência: o cotidiano das vivências com a morte e o morrer pelos profissionais de saúde
}

\author{
Emergency Room: the daily experiences with the death and dying for the health care professionals
}

Sala de Urgencia: el cotidiano de las vivencias con la muerte y el morir por los profesionales de salud

\author{
Geraldo Magela Salomé', Amanda Cavali', Vitória Helena Cunha Espósito" \\ 'Hospital Geral Vila Nova Cachoeirinha. São Paulo, SP \\ "Universidade Católica de São Paulo. Faculdade de Educação. São Paulo, SP
}

Submissão: $05 / 08 / 2008$

Aprovação: 31/08/2009

\section{RESUMO}

Objetivo: conhecer as experiências vivenciadas pelos profissionais de enfermagem Que trabalham e convivem com a morte em unidade de emergência, possibilitando momentos de reflexão sobre seus significados. Método: Trata-se de uma pesquisa Qualitativa, do tipo fenomenológica, realizada com o recurso de entrevistas com profissionais de enfermagem Que atuam na sala de emergência de um Hospital Estadual, na cidade de São Paulo. Resultados: A análise dos dados permitiu evidenciar que esses profissionais, ao vivenciarem o processo de morte e morrer, expressam sentimentos de tristeza, impotência, perda, fracasso e medo. Conclusão: o profissional de enfermagem não está preparado para lidar com tais situações, pois assume um compromisso pela preservação da vida. Também foi possível observar que os sujeitos da pesquisa vivenciam o luto pela morte dos pacientes aos Quais prestam cuidados.

Descritores: Assistência de enfermagem; Morte; Pesquisa Qualitativa.

\begin{abstract}
Objective: To know the feelings experienced by the nursing professionals who work together and with the death in the emergency unit, providing a moment of reflection on the significance of these. Method: This is a Qualitative research, with phenomenological approach, held from through interviews with nursing professionals who work in the emergency room in a public hospital in the city of São Paulo. Results: The analysis of the data collected made it possible to realize that the professionals to vivenciarem the process of death and dying, showed feelings: sadness, helplessness, loss, failure and fear. Conclusion: the professional nursing is not prepared to deal with such feelings because assume a commitment for the preservation of life. Also, we can say that the subjects of the search live the mourning with the death of patients who care.
\end{abstract}

Descriptors: Nursing care; Death; Qualitative research.

\section{RESUMEN}

Objective: Para saber las sensaciones experimentadas por los profesionales del oficio de enfermera Que trabajan juntos y con la muerte en la unidad de la emergencia, proporcionando un momento de la reflexión en la significación de éstos. Método: Esto es una investigación cualitativa, con las razones fenomenológicas, llevadas a cabo a partir de entrevistas con profesionales de enfermería Que trabajan en la sala de urgencia de un hospital público en la ciudad del São Paulo. Resultados: El análisis de los datos permitido realizar Que los profesionales al vivenciarem el proceso de la muerte y de morir, demostrado sensaciones: tristeza, desamparo, pérdida, falta y miedo. Conclusión: el oficio de enfermera profesional no está preparado para ocuparse de tales sensaciones porque asuma una comisión para la preservación de la vida. También, podemos decir que viven los temas de la búsqueda el luto con la muerte de los pacientes Que cuidan. Descriptores: Atención de enfermería; Muerte; Investigación cualitativa. 


\section{INTRODUÇÃO}

A morte incomoda e desafia a pretensa onipotência humana, podendo conter vários significados, de acordo com a formação estrutural, cognitiva e religiosa de cada pessoa. Porém, na sociedade contemporânea ocidental, a finitude é pouco discutida, excluída, gradativamente, do âmbito social, tornando-se um tabu.

Durante a idade Média, a morte era um fenômeno comum e natural; ocorria em casa junto com os familiares, mas, com o passar do tempo e o avanço da tecnologia, deslocou-se para o hospital. No século XX, houve uma profunda transformação revolucionária na forma de lidar com a morte, a Qual deixa de ser parte inalienável do curso da vida, passando a ser ocultada no cotidiano, com aparente indiferença ${ }^{(1,2)}$.

Entretanto, atualmente, com novas transformações ocorridas em várias esferas da sociedade, cada vez mais aceleradas, e com a implementação do SUS, observa-se uma tendência do retorno à morte no domicílio, até mesmo por motivos econômicos para as Instituições. Assim, os profissionais que atuam nas Unidades Básicas de Saúde também vêm se deparando com esse lidar com a morte.

A morte é um fato inevitável, inerente ao ciclo dos seres vivos, (nascer, crescer, morrer); cientificamente, é deixar de existir ${ }^{(3)}$. Portanto, ao refletirmos sobre ela, sentimentos, geralmente pouco discutidos, são gerados.

O ser humano está inserido em um mundo complexo e repleto de contradições, onde a conscientização acerca de Questões pertinentes ao seu existir necessitam ser consideradas. No entanto, observa-se ser comum não pensar na morte enQuanto uma certeza da vida do homem ${ }^{(4)}$. Há autores Que definem o final da vida como um processo progressivo, com diminuição e alterações das funções vitais Que culminam com a morte ${ }^{(5)}$; para outros, ela tem sido encarada como um acontecimento, terrível, um medo universal e este sentimento é parte natural do comportamento humano ${ }^{(6)}$.

O "cuidar" é algo inerente ao ser humano. Cuidamos do nascimento até à morte; a enfermagem é uma profissão direcionada ao cuidar e norteada por princípios científicos, técnicos, administrativos e éticos. Assim, é uma ciência essencialmente humana, baseada em fundamentações e práticas do cuidar do ser humano em todo o curso da vida. Nesse sentido, os profissionais de enfermagem têm um papel diante da pessoa em processo de morte; o cuidado é uma Questão presente em seu cotidiano, o Que, pela sua proximidade com a pessoa doente, pode causar-lhes sentimentos como tristeza, frustração, raiva, fuga e até negação, por não conseguirem manter a vida ${ }^{(3,7)}$.

A enfermagem tem como filosofia assistir ao paciente holisticamente. Portanto, esse assistir abrange as necessidades relacionadas às esferas física, emocional, social e espiritual da pessoa doente. No momento da morte, emerge a reflexão sobre a necessidade espiritual do doente, pois isso se reveste de grande importância para o alívio do sofrimento das pessoas envolvidas em um processo de morrer.

No âmbito acadêmico, a temática da morte e sua vivência são, de certa forma, relegadas ou excluídas da formação dos enfermeiros, não havendo uma disciplina específica sobre o tema Que valorize e ressalte a esfera humanística e filosófica, potencializando a sensação de que somente o restabelecimento da saúde faz parte de uma boa assistência. Naturalmente Que não devemos desvalorizar os centros de tratamento, com os inúmeros recursos disponíveis na tentativa de manutenção e recuperação da vida, mas, faz-se necessário valorizar, também, a temática da morte, discutindo-a e abrindo novos caminhos para reflexões.

Muitos profissionais de enfermagem sentem-se despreparados para lidarem com situações Que envolvem a morte, devido a essa ausência de reflexão e total silêncio, por parte da academia, a Qual se atém ao tecnicismo, acreditando Que a vivência possa levar os profissionais a descobrirem o Que é relevante neste processo ${ }^{(8)}$.

A concepção do Que venha a ser um bom enfermeiro tem sido aQuele Que, com o passar dos anos de profissão, passa a ser "frio" em suas ações ${ }^{(9)}$. Essa situação está presente no cotidiano, pois é comum haver um improcedente julgamento no sentido de Que, Quando o enfermeiro expressa suas emoções, seja considerado imaturo profissionalmente.

Ser enfermeiro significa ter, como foco profissional, o homem. Pode-se considerar Que a maior gratificação no trabalho do profissional consiste, como já mencionado, em preservar a vida. Para os Que atuam em setores críticos, como é o caso das unidades de emergência, essa concepção é bastante acentuada ${ }^{(10)}$.

Os profissionais Que atuam em unidades de emergência convivem, diariamente, com pacientes em condições de saúde instáveis. Portanto, para sua atuação, devem receber treinamento, conhecimento técnico e científico, pois as salas são equipadas com monitores portáteis, respiradores, desfibriladores, gerador de marca passo e material completo de atendimento ao trauma. Esse cenário sinalizador de manutenção da vida pode gerar situações de estresse. principalmente Quando o paciente morre.

Estes profissionais, por estarem tão próximos de situações emergenciais, podem ser acometidos por um estado de ansiedade, devido à convivência com a dor e sofrimento, por serem os primeiros a lidarem e sentirem a morte, uma vez Que prestam assistência, desde os procedimentos mais simples aos mais complexos, cuidando, principalmente, Quando o paciente encontra-se em estágio final ${ }^{(11,12)}$. Alguns autores mencionam Que essas pessoas estão mais sujeitas a um processo de desgaste profissional, conhecido, na literatura, como Síndrome de Bournout ${ }^{(13,14)}$.

Assim, a morte faz parte do seu cotidiano, principalmente nas unidades de emergência. Partindo dessas evidências, surge a seguinte Questão: Quando todos os recursos se esgotarem e o paciente, internado na sala de emergência, morrer, Qual o sentimento expresso pelos profissionais de enfermagem?

Do exposto, o objetivo do presente estudo é apreender os sentimentos vivenciados pelos profissionais de enfermagem Que trabalham e convivem com a morte em unidade de emergência, proporcionando-lhes um momento de reflexão sobre o tema.

\section{METODOLOGIA}

\section{Referencial Metodológico}

A opção foi pela pesQuisa de campo, de natureza Qualitativa, modalidade fenomenológica, pois, além de enfocar o pré-reflexivo a partir do Que é experienciado pelos sujeitos (profissionais de enfermagem), busca desvelar o que lhes é significativo, apreendendo os sentimentos dessas pessoas; para essa apreensão é imprescindível Que pesquisador e pesquisados estabeleçam uma relação empática. Enfim, a fenomenologia possibilita a observação direta da experiência 
subjetiva do ser. O foco de atenção da pesQuisa Qualitativa estará direcionado para o específico, o particular e o individual do fenômeno, procurando, assim, compreendê-lo.

A abordagem Qualitativa é referida como aquela capaz de abranger a Questão dos significados e da intencionalidade ligada aos atos, às relações e às estruturas sociais, permitindo alcançar a realidade social para além do que pode ser observado e Quantificado; compreende as relações sociais, capta as relações objetivas vivenciadas pelos atores, atribuindo-lhes significados, uma vez que caminha para o universo das significações, motivos, aspirações, crenças e valores ${ }^{(15)}$.

A fenomenologia, proposta por Husserl, no inicio do século XX, na Alemanha, é definida como ciência descritiva, rigorosa, concreta, Que mostra e explicita o ser nele mesmo, preocupandose com a essência do vivido ${ }^{(16)}$.

O lema de Husserl "volta às coisas mesmas" é uma tentativa de aproximação às coisas, sem preconceitos ou pressupostos interpretativos à priori. Assim, a fenomenologia é definida como "ciência dos fenômenos", sendo fenômeno compreendido como o Que é imediatamente dado em si mesmo à consciência, ou seja, aQuilo Que surge para uma consciência, o Que se manifesta para essa consciência como resultado de uma interrogação ${ }^{(17)}$. Ela não estará preocupada com os fatos ou causalidade, mas busca dirigirse ao mundo e apreendê-lo a partir de uma outra ordem - a Qualitativa. Preocupa-se com a essência do fenômeno a partir da experiência vivida e sua investigação busca interrogar a coisa mesma $^{(18)}$.

Considerando Que a fenomenologia visa à compreensão, há de se considerar que a enfermagem necessita olhar para o homem a Quem cuida em sua totalidade existencial. Também se faz necessário direcionar nosso olhar para o homem - profissional de enfermagem e, nesse sentido, merecem destaque, pelo seu conviver cotidiano com situações de morte, os profissionais Que atuam em salas de emergência, enquanto seres-situados-no-mundo, cabendo-lhes atribuir significado à essa experiência. Por meio de discursos obtidos, propusemo-nos a compreender o não mostrado, o velado, o mundovida das pessoas, sujeitos da pesquisa, buscando, assim, a essência do fenômeno por elas vivenciado.

Diante desses profissionais, afetados em sua existência por um cotidiano conviver com a morte, em seu impacto sobre eles, vislumbramos, na fenomenologia, a possibilidade de compreensão de algumas facetas da existência dessas pessoas, enquanto "seres lançados no mundo", no Qual convivem e compartilham experiências.

O cenário da Investigação e a Observância à Dimensão Bioética

A pesquisa foi realizada em uma Unidade de Emergência de um hospital geral e estadual de grande porte, localizado na região norte de São Paulo. A escolha dessa instituição deve-se ao fato de se tratar do local onde realizamos o estágio curricular da graduação, em Pronto Socorro, iniciando as observações em relação ao fenômeno interrogado.

A sala de emergência conta com seis leitos. Atuam nesse setor médicos, enfermeiros, auxiliares de enfermagem, totalizando 16 profissionais para Quatro turnos de trabalho.

A nossa proposta foi a de entrevistar enfermeiros e auxiliares de enfermagem, ambos os sexos Que trabalham na sala de emergência já situada.

O convite para participar da pesquisa foi realizado previamente e após aceitação dos funcionários, as entrevistas foram agendadas e realizadas na própria unidade, com a preocupação de não interferir nos horários de procedimentos e garantir a privacidade dos sujeitos da pesquisa. Antes de iniciar a coleta dos dados, o projeto foi cadastrado no Sisnep e avaliado pelo Comitê de Ética em Pesquisa da Universidade Nove de Julho, sendo aprovado segundo parecer CEP: 157658/2008. Também foi solicitada autorização para realização do estudo ao núcleo de pesQuisa do hospital.

Os sujeitos foram informados a respeito da proposta e da importância da pesQuisa e receberam explicações sobre a forma de condução das entrevistas, o anonimato e sobre a possibilidade de se desvincularem da pesquisa a QualQuer momento. Após os participantes terem assinado o Termo de Consentimento Livre Esclarecido, iniciamos as entrevistas. Cada um dos participantes recebeu um pseudônimo.

As entrevistas foram agendadas e realizadas na unidade de emergência no mês de fevereiro de 2008, com a preocupação de não interferir nos horários habituais dos procedimentos da enfermagem junto aos pacientes. Foram realizadas a partir de uma pergunta aberta, tendo como Questão norteadora: Quais foram os sentimentos vivenciados por você, após a constatação do óbito?

As entrevistas foram gravadas com suas anuências e, posteriormente transcritas, de acordo com a Questão norteadora. Eles relataram e se expressaram livremente sobre o fenômeno vivenciado, cujo significado está na própria experiência por eles vivida. Coletados os depoimentos, observamos Que a saturação dos dados (discursos) ocorreu ao totalizarmos 14 entrevistas.

A análise compreensiva dos relatos representou um momento de intersubjetividade, de encontro entre nosso pensar enquanto pesquisador e o dos sujeitos participantes, o Que possibilitou a explicitação das diferentes esferas ou dimensões apreendidas nas descrições.

Foi iniciada a leitura de cada entrevista procurando familiarizarme com o todo. A leitura dos discursos foi realizada buscando sempre o mundo do entrevistado, estando aberta à sua fala, à sua escuta.

Posteriormente, retornei aos discursos atentamente, focalizando a temática estudada, possibilitando o emergir das unidades de significado. Uma unidade de significado é, em geral, uma parte da descrição, cujas partes relacionam-se umas com as outras, indicando momentos significativos do discurso. Dessa forma, o pesquisador estará preocupado em captar não só o Que se mostra de maneira clara, mas também em ter a sensibilidade para captar os significados atribuídos às experiências vividas pelos sujeitos.

Nesse percurso, as unidades de significados foram identificadas e agrupadas em cada discurso, objetivando aproximar o Que, de comum, emergiu dessa experiência. Em seguida, busquei pelas convergências temáticas, as idiossincrasias e as divergências encontradas nos discursos individuais, de forma a agrupar as unidades de significados semelhantes. A partir das convergências provenientes da análise ideográfica, foram construídas as confluências temáticas, Que sinalizam para a essência da estrutura geral do fenômeno, o Qual veio a constituir-se na confluência nomotética. Realizo, a seguir, a análise compreensiva/interpretativa dos depoimentos. Foram Quatro as confluências temáticas: 
"Expressando sentimentos diante da morte do paciente;

"Vivenciado o preparo do Corpo;

"Significado da Morte;

* Crenças relacionadas à morte.

\section{RESULTADOS E DISCUSSÃO}

\section{Confluência temática: "Expressando sentimentos diante da morte do paciente".}

Com base nas confluências temáticas, observei e, ao mesmo tempo, aproximei-me do mundo - vida dos profissionais de enfermagem Que prestam assistência ao paciente atendido na sala de emergência, o Qual veio a morrer. Os entrevistados, ao permitirem um momento para reflexão sobre suas existências, como seres humanos e como cuidadores, expressaram sofrimento. Os sentimentos mais ressaltados foram impotência, perda, tristeza e frustração. As falas abaixo evidenciam estes sentimentos:

"Após um atendimento de emergência, com a constatação do óbito, eu fico triste porque poderia ser um parente da gente ou eu mesma! Sinto uma sensação de perda.. eu não me sinto bem, então, a gente fica chateado". (Discurso AC)

"Eu trabalho muito tempo na sala de emergência mas eu ainda choro Quando eu perco um paciente, eu ainda sofro.....mexer com a morte é uma coisa Que me incomoda muito, mesmo sabendo que sou uma profissional". (Discurso BR)

"Quando um paciente da emergência evolui a óbito, a gente sente bastante, eu sinto tristeza e frustração". (Discurso JL)

"Já fazem 28 anos Que trabalho na emergência, mas fico triste, chateada, meu coração fica apertadinho, sabe? Escorre até uma lágrima, assim, escondida”. (Discurso FA)

Os profissionais de enfermagem, mesmo trabalhando há algum tempo na emergência, não se habituam à situação de morte e muitos não compartilham esses sentimentos com seus colegas, aumentando, ainda mais, a tensão. Quando os profissionais sentemse impotentes eles também choram, pois o envolvimento é tão grande que acreditam ser o momento de expressar o sofrimento para aliviar sua própria dor ${ }^{(19)}$.

A tristeza é um sentimento intrínseco ao ser humano; todas as pessoas a sentem, em algum momento de suas vidas e, pelo fato do profissional Que atua em emergência estar muito próximo às situações críticas, está mais vulnerável a elas. O contato constante com a morte os angustia profundamente, possivelmente porque lhes retira as defesas construídas durante toda a vida, no sentido de negar a morte ${ }^{(20)}$.

É relevante captar os sentimentos vivenciados na prática dos enfermeiros. É sabido Que o autoconhecimento é um processo importante a ser explorado de forma a melhor lidar com situações Que impliquem manifestações de emoções profundas, principalmente relacionadas à morte ${ }^{(8)}$

Apesar de todo o esforço na tentativa do resgate à vida, o profissional sente-se como não tendo cumprido o seu objetivo de "salvar vidas", conforme relatam nas falas a seguir:
"No atendimento de emergência, Quando um paciente vai a óbito, acaba ficando um sentimento de perda por você ter tentado e não ter conseguido...gente acaba ficando chateado pra caramba... é complicado, você fica com essa sensação de impotência". (Discurso WO)

"Depois de horas de emergência, a gente fica decepcionada se o paciente morre, porque tudo aquilo que você fez foi em vão; o Que você Queria era ele ali, mas você não conseguiu; é um sentimento de perda". (Discurso DG)

Descrevem sentimentos como decepção, impotência e perda. Apesar desse confronto com a morte em seu cotidiano de trabalho, encontram dificuldade para encará-la. Sentem-se responsáveis pela manutenção da vida de seus pacientes, considerando a morte como um insucesso do tratamento, um fracasso da equipe, o qual gera angústia $^{(2 l)}$.

Essa situação é decorrente da exclusão temática da morte durante a formação dos profissionais da saúde, na Qual não são preparados para lidar e refletir sobre o tema ${ }^{(20,21)}$. A formação acadêmica, centrada na preservação da vida, particularmente na cura das doenças, retira a maior fonte de gratificação Quando, em seu cotidiano de trabalho, ao lidarem com situações Que envolvem a morte e o morrer; sentem-se despreparados e tentam delas se afastarem $^{(22,23)}$.

\section{Confluência temática: “ Vivenciado o preparo do Corpo"}

O final da vida expressa o limite da nossa finitude humana, sendo Que a equipe de enfermagem é a primeira a lidar e sentir a morte. Assim, o preparo do corpo é o último cuidado realizado pelo profissional à pessoa da Qual cuidou em vida. Referem Que esse momento suscita muitas reflexões:

\section{“ A pior parte da enfermagem é em relação ao preparo do corpo porque é muito invasivo, poderia ser um parente seu ou próprio você!". (Discurso $A C)$}

"Durante o preparo do corpo eu não me sinto bem, eu estar fazendo, eu acho que principalmente porque o meu primeiro tamponamento foi o meu próprio pai... foi uma experiência péssima". (Discurso WO)

“O preparo do corpo é a única parte da enfermagem Que ninguém gosta; é algo muito invasivo, Que a gente mal sabe que, algum dia, vai ser a gente ou alguém da tua família; é difícil assistir ou ver". (Discurso JL)

Percebe-se Que o preparo do corpo é entendido como um procedimento técnico, ao Qual o profissional não se habitua a realizar pois, além de ser invasivo, naQuele momento possibilita Que reflita sobre sua própria finitude, o Que gera angústia.

O momento do preparo de um corpo após a morte consiste em difícil tarefa, a Qual transcende a relação direta enfermeiro/paciente, estendendo-se também à família. Exige, nos dias atuais, uma redimensão dos sentimentos dos profissionais sobre a morte e o morrer e também sobre o a respeito à vida ${ }^{(20)}$.

Os profissionais de enfermagem revelam Que devem ser éticos, inclusive pelo fato de ser o corpo de seu paciente, após haver 
morrido. Eis algumas falas:

“...não preparo o corpo mecanicamente, tem Que ter o respeito. " Discurso A.C

“... sem brincadeira, comentários não gosto disso, não faço; $e$ é nessa hora Que você percebe Que você não é nada e Que somos todos iguais". (Discurso TV)

"Eu somente procuro respeitar, eu me coloco, assim, como se fosse a minha mãe ou um filho meu ali, então, eu não vou ficar cantando e nem rindo; mas, é apenas um corpo". (Discurso BR)

“Durante o preparo do corpo, eu preparo com, respeito porQue ele tem nome, uma identidade, ele tem uma família, ele tem uma historia. Então, o corpo não é um objeto, mas como um ser, ele não está respirando, mas é um corpo... é um ser". (Discurso XN)

Os discursos revelam Que o respeito está presente no ato de preparo do corpo, pois reconhecem Que, nesse momento, a seriedade é primordial, atentando que o corpo, mesmo não mais respirando, é um ser. A vida e a morte são percebidos como processos interligados, sendo o corpo, mesmo desprovido de vida, merecedor de respeito ${ }^{(24)}$.

\section{Confluência temática: "Significado da Morte"}

Esta área temática trouxe a percepção de Que a morte é um tema cercado por mistérios e rupturas. Imaginar Que sonhos, expectativas, objetivos foram rompidos é uma experiência Que revela a impotência dos seres humanos. Nesse sentido, as falas dos participantes são expressivas:

"A morte é uma coisa meio... não tem explicação". (Discurso $\mathrm{AC})$

"Eu sei Que a morte é uma fatalidade e todo mundo vai morrer mais cedo ou mais tarde , mais, na minha cabeça, é uma coisa Que eu não entendo muito". (Discurso BR)

Os pesquisados relatam não ter muito claro o Que explica, efetivamente, o final da vida. Existem vários fatores Que interferem no modo como reagimos à perdas como a morte, os Quais incluem idade, saúde, cultura, crenças religiosas e vida social.

Percebe-se que, mesmo considerando que a morte faz parte do curso natural da vida, permanece sendo encarada como fatalidade, algo Que não tem explicação e Que vai muito além do não funcionamento dos órgãos. Exemplificando:

"Morte para mim é passagem... é um mistério só Deus pode saber o porque chegou o tempo. E que nós é que temos que aceitar, seja ela da maneira Que for". (Discurso IL)

"Para mim, a morte é um descanso. Claro que cada um de nós temos as nossas obrigações aqui na terra. (Discurso SZ)

“A morte é uma perda realmente para a família mas, também, é um descanso eterno". (Discurso FA)

A representação de significado palavra morte desdobra-se em outras como passagem, perda e descanso eterno. $\mathrm{O}$ aspecto passagem denomina-se transitório entre o mundo material e espiritual. A morte é vista como um evento Que ocorre com todos, num futuro, portanto, supostamente desconhecido, trazendo à tona a emoção do medo, o mistério e o não familiar ${ }^{(1,19)}$.

\section{Confluência temática: "Crenças relacionados à morte"}

As reações e percepções Que os profissionais de enfermagem têm diante da morte estão relacionadas ao tipo de cultura, religião e educação. Vejamos as falas nesse sentido:

“... dizem as pessoas espíritas que, Quando a gente está cuidando daquele corpo, o próprio espírito da pessoa está do lado, vendo o Que está acontecendo". (Discurso AC)

“eu tenho a crença de que ele não está sentindo absolutamente mais nada; espiritualmente falando, aQuele corpo não tem mais o Que fazer; o que a gente pode fazer é antes do corpo parar. $O$ sentimento e os cuidados têm Que ser antes". (Discurso BR)

“Morte é a passagem que todos nós temos que passar. Depois disso, eu não oro mais para o Que partiu, somente para a família porque eles vão precisar dessa força; mas, para o Que foi é apenas um corpo que já seguiu o seu destino". (Discurso IL)

As falas revelam a existência de vários elementos e concepções espirituais; alguns crêem Que o espírito fica vagando; outros, Que a alma vai para um descanso, eterno, onde permanecerá para sempre. Portanto, independentemente da crença, sempre haverá interligação entre a matéria (corpo) e espírito (alma).

No entanto, cada um tem sua filosofia de vida, a Qual o ajudará a enfrentar e superar o temor da morte, conforme relatam os sujeitos:

"Quando eu preparo o corpo, eu faço uma oração... e pedindo pra que Deus dê descanso para aquela alma...(* Choro). (Discurso WO)

"Morte, espiritualmente falando, cada pessoa tem uma crença e acredita de um jeito; eu acredito que o espírito se desligou daqui, ele foi para onde Deus mandou, não fica aqui vagando. Algumas pessoas dizem que ele fica ali perto do corpo mas, para mim, não tem nada disso". (Discurso LZ)

“A morte para mim é um paraíso que você vai sair dessa vida atribulada e vai para o paraíso com muita alegria e com muita paz.... porque nós, seres humanos, somos corpo e alma, saindo a alma, o corpo é um pedaço de carne Que não vale nada". (Discurso FA)

São variados os conceitos e concepções de morte, mas evidenciase Que todos têm algo em comum, abordando a cessação das funções vitais e separação entre corpo e alma. A morte, como limite, possibilita o aflorar de sentimentos negativos, mas, por outro 
lado, tem interligação com a imortalidade; nesse momento, a religião é de extrema importância. O papel da religião é, em parte, socializar e dirigir os ritos de morte como forma de lidar com o temor ${ }^{(2)}$.

\section{CONSIDERAÇÕES FINAIS}

Na condição de pesquisadora, tive a preocupação em apreender os sentimentos vivenciados pelos profissionais de enfermagem durante a morte dos pacientes atendidos na sala da emergência; assim, foi possível compreender e apreender como esses profissionais vivenciaram o processo de morte de pacientes, expressando sentimentos de fracasso, perda, impotência, tristeza e medo. Isto ocorre porQue o profissional é um ser com a condição ontológica básica de ser-no-mundo e, nessa perspectiva, é um serno-mundo-com-os-outros. Talvez esses sentimentos possam ter aflorado porQue, todo profissional, durante sua formação, aprende e, até mesmo na colação de grau, faz um juramento, no Qual assume seu compromisso com a vida, pela sua preservação e com o cuidado humano.

Pode-se também afirmar, conforme expressam os discursos, Que os profissionais de enfermagem agregam o sentimento de luto no caso de morte; isto se compreende pelo fato de serem pessoas, ou seja, humanos, Que também expressam emoções e têm suas limitações. Nesse sentido, trabalhar o luto entre familiares e membros da equipe vem merecendo a recomendação de autores.

Acredita-se que novas pesquisas sobre o tema, à luz de outros referenciais filosóficos, possam ser realizadas. $\mathrm{Na}$ ótica fenomenológica, chegar à essência de um fenômeno não é algo total e acabado, pois os fenômenos não se esgotam em uma perspectiva, mas se modificam a cada olhar. Assim, é meu compromisso divulgar o conhecimento produzido por esse estudo junto aos profissionais Que atuam na instituição onde a pesquisa foi realizada, bem como nas universidades e outros serviços, com vistas a sensibilizar os distintos setores educacionais para a dimensão pedagógica do tema da morte.

No momento atual, muita ênfase tem sido dada à humanização em saúde e, nesse sentido, o cuidado com o cuidador reveste-se de importância ímpar. O presente estudo constitui-se em um alerta para Que atentemos para a saúde dos profissionais de enfermagem Que atuam em setores críticos, como é o da sala de emergência.

\section{REFERÊNCIAS}

I. Fernandes MFO, Freitas GF. Olhando para o processo da morte diante da práxis ética existencial e profissional. In: $56^{\circ}$ Congresso Brasileiro de Enfermagem; 2004; Gramado(RS), Brasil. Porto Alegre: ABEn-RS; 2004.

2. Oigman G. Tabu da morte. Cad Saúde Pública 2007; 23(9): 102-8.

3. Beserra GMG, Santana MG, Araujo AC. Morte: uma reflexão na educação em enfermagem. Rev Tecn Cien Enferm 2006; 4(15): 91-6.

4. Lunardi ZM, Celich KLS. Convivendo com a morte e o morrer no cotidiano de cuidado da Unidade de Terapia Intensiva. Rev Nursing 2006; 9 (92): 617-21.

5. Junior AS, Rolim LC, Morrone LC. O preparo do médico e a comunicação com familiares sobre a morte. Rev Assoc Méd Bras 2005; $51(1)$ : 1 1-6.

6. Palú LA, Labronici LM, Albini L. A morte no cotidiano dos profissionais de enfermagem de uma unidade de terapia intensiva [monografia]. Curitiba: Universidade Federal do Paraná; 2004.

7. Gasperini P, Radünz V. Cuidar de si mesmo: essencial para enfermeiros. Rev Min Enferm 2006; 10(1): 64-9.

8. Aguiar IR. O envolvimento do enfermeiro n processo de morrer de bebês internados em Unidade Neonatal. Acta Paul Enferm 2006; 9(2): 131-7.

9. Reinaldo AMS. O pacote de emoções geradas pelo ensino da técnica de preparo do corpo pós morte: relato de experiência. Revista Eletrônica Enferm 2005; 7(1): 95-8.

10. Batista KM, Bianchi ERF. Estresse do enfermeiro em unidade de emergência. Rev Latino-Am Enfermagem 2006; 14(4): 53439.

1 1. Brêtas JRS, Oliveira IR, Yamaguti L. Reflexões de estudantes de enfermagem sobre morte e o morrer. Rev Esc Enferm USP 2006; 40 (4): 477-83.

12. Martino MMF, Misko MD. Estados emocionais de enfermeiros no desempenho profissional em unidades críticas. Rev Esc Enferm USP 2004; 38(2): 16I-7.

13. Pitta, A. Hospital: dor e morte como ofício. São Paulo: Hucitec; 1990.

14. Popim RC, Boemer MR. O cuidar em oncologia: diretrizes e perspectivas. Botucatu: Editora UNESP; 2006.

15. Minayo MCS. O desafio do conhecimento: pesquisa Qualitativa em saúde. São Paulo: Hucitec; 2004.

16. Capalbo C. Fenomenologia e ciência humana. Londrina: UEL; 1996.

17. Martins I, Bicudo M. A pesquisa Qualitativa em psicologia: fundamentos recursos básicos. São Paulo: Centauro; 2003.

18. Espósito VHC. Construindo o conhecimento da criança adulto, uma perspectiva interdisciplinar? São Paulo: Martinari; 2006.

19. Gutierrez BAO, Ciampone MHT. Profissionais de enfermagem frente ao processo de morte em unidades de terapia intensiva. Acta Paul Enferm 2006; 19(4): 456-61.

20. Shimizu HE. Como os trabalhadores de enfermagem enfrentam o processo de morrer. Rev Bras Enferm 2007; 60(3): 257-62

21. Vieira MA, Souza SI, Sena RR. Significado da morte para os profissionais de enfermagem Que atuam no CTI. Rev Min Enferm 2006; 10 (2): 151 -9.

22. Bellato R, Carvalho EC. O jogo existencial e a ritualização da morte. Rev Latino-Am Enfermagem 2005; 13(1):99-104.

23. Bellato R, Araújo AP, Ferreira HF, Rodrigues PF. A abordagem do processo do morrer e da morte feita por docentes em um curso de graduação em enfermagem. Acta Paul Enferm 2007; 20(3): 255-63.

24. Bernieri I, Hirdes A. O preparo dos acadêmicos de enfermagem brasileiros para vivenciarem o processo morte-morrer. Texto Contexto Enferm 2007; 16(1):89-96. 